\title{
LA SALUD AMBIENTAL MEDIDA A PARTIR DE DATOS CENSALES. UNA MIRADA SOBRE EL AREA METROPOLITANA DEL GRAN RESISTENCIA Y PRESIDENCIA ROQUE SAENZ PEÑA
}

\author{
ENVIRONMENTAL HEALTH MEASURE FROM CENSUS DATA. A LOOK ON THE \\ METROPOLITAN AREA OF GRAN RESISTENCIA AND PRESIDENCIA ROQUE SAENZ \\ PEÑA
}

\author{
Dra. Lic. Liliana Ramírez \\ Iramirez@hum.unne.edu.ar \\ Prof. Romina Soledad Claret \\ claret_romina@hotmai.com \\ Departamento de Geografía \\ Facultad de Humanidades
}

\section{Resumen}

Tras la Cumbre de la Organización de Naciones Unidas del año 1992 en Río de Janeiro, en la cual se aprobó la Declaración de Río sobre el Medio Ambiente y el Desarrollo, gran cantidad de sustantivos se adjetivaron con el término "ambiente": política ambiental, desarrollo ambiental, tecnología ambiental, salud ambiental, economía ambiental, educación ambiental, recurso ambiental, y la lista podría seguir, si bien muchos de ellos ya se habían definido anteriormente, la Cumbre profundizó y dejó en evidencia la perspectiva ambiental. Esta Reunión significó un punto de inflexión en las administraciones, locales, provinciales y nacionales y, en muchos casos, el ambiente se tornó una cuestión constitucional. En la Argentina el artículo $41^{\circ}$ expresa: "Todos los habitantes gozan del derecho a un ambiente sano, equilibrado, apto para el desarrollo humano y para que las actividades productivas satisfagan las necesidades presentes sin comprometer las de las generaciones futuras; y tienen el deber de preservarlo..."', aquí es como apreciamos la explícita relación entre salud y ambiente. Según la Organización Mundial de la Salud, de la relación salud-ambiente surge la atención sobre la Salud Ambiental de la población, que estará relacionada con los factores físicos, químicos y biológicos que podrían incidir en la salud y que se basa en la prevención de las enfermedades y en la creación de ambientes saludables (OMS, 2001). La ciencia geográfica tiene mucho para aportar al conocimiento y monitoreo de la Salud Ambiental, Jaime Breilh (1988) señala "la Geografía deviene frente a la salud, no un simple reservorio de climas, contaminantes, de microbios, de vectores de transmisión infecciosa, etc., sino un espacio históricamente estructurado, donde también se expresan las consecuencias benéficas y destructivas de la organización social". ".

Así, para evaluar las diferentes dimensiones de la relación salud-ambiente de una población se utilizan Indicadores de Salud Ambiental, definidos por Briggs (1996) como "la expresión de la vinculación entre medio ambiente y salud, enfocando algún aspecto concreto en el ámbito de políticas o administración, y presentada en una forma que facilite su interpretación" "iii. Precisamente esta cuestión es la que consideramos una importante debilidad al momento de querer dar cuenta de la Salud Ambiental, ya que los datos básicos disponibles para construir indicadores o elaborar índices son relativamente escasos.

En esta contribución se expone una propuesta de Índice de Salud Ambiental (ISA) basado en datos censales generados por el INDEC. Si bien la propuesta corresponde al año 2001, tenemos la expectativa de que en poco tiempo podamos volver a elaborarlo para una fecha más próxima, como puede ser la de 2010. Territorialmente anclamos el aporte a escala urbana presentando el resultado para el Área Metropolitana del Gran Resistencia y Presidencia Roque Sáenz Peña.

Publicado en formato digital: Dra. Lic. Liliana Ramírez y Prof. Romina Claret. LA SALUD AMBIENTAL MEDIDA A PARTIR DE DATOS CENSALES. UNA MIRADA SOBRE EL AREA METROPOLITANA DEL GRAN RESISTENCIA Y PRESIDENCIA ROQUE SAENZ PEÑA. Revista Geográfica Digital. IGUNNE. Facultad de Humanidades. UNNE. Año 11. No 21. Enero - Junio 2014. ISSN 1668-5180 Resistencia, Chaco. En: http://hum.unne.edu.ar/revistas/geoweb/default.htm 
En lo referente a la metodología, a partir de datos de valores relativos simple se procedió a desarrollar un Modelo de Utilidad Multiatributo (MAUT) de tipo aditivo para cada una de las unidades espaciales estudiadas. Así, una vez logrado el ISA se extrajo la potencial población para cada una de las categorías consideradas.

\title{
Palabras claves:
}

Salud Ambiental - Índice de Salud Ambiental - Chaco - Modelo de Utilidad Multiabtributo.

\begin{abstract}
During the summit meeting of the United Nations in 1992 in Rio de Janeiro, where was approved the Rio Declaration on Environment and Development, the term "environment" has been mentioned many times: environmental policy, environmental development, environmental technology, environmental health, environmental economy, environmental education, environmental resource, and the list could go on, although many of them have already been defined, the summit meeting deepened the environmental perspective. This assembly marked inflection point in the administrations, local, provincial and national, and in many cases, the environment became a constitutional issue. In Argentina the article 41 express: "All citizen shave the right to a healthy and balanced environment for human development and productive activities without compromising future generations; and have the duty to preserve it..," that's how we appreciate the explicit connection between health and environment. According to the World Health Organization, of the health-environment relation arises the Environmental Health of population, will be related to the physical, chemical and biological factors that could affect health and which is based on the prevention of disease and creating healthy environments (WHO, 2001). Geographical science can contribute to knowledge and monitoring of Environmental Health, Jaime Breilh (1988) says "Geography is in the field of health, not just a reservoir of climates, pollutants, microbes, infectious vector transmission, etc..., but a historically structured space, where also the beneficial and destructive consequences of social organization are expressed."

Thereby, to evaluated different dimensions of health-environment relationship in a population Environmental Health Indicators are used, defined by Briggs (1996) as "the expression of the relation between environment and health, focusing on a specific aspect of the field of policy or administration, and presented in a way that facilitates their interpretation." Precisely this point is which we consider a major weakness when the main aim is analysis Environmental Health, because the available database to develop indicators indices are relatively scarce.

In this paper, we exposed a proposed of Environmental Health Index (ISA) based on census data generated by INDEC. Although the proposal is for the year 2001, we have the expectation of redeveloped to a closer date, as may be the 2010. The contribution is about a urban level we present the results of the Metropolitan Area and Presidencia Roque Sáenz Peña.
\end{abstract}

About methodology, from relative values we proceeded to develop an additive Multiattribute Utility Model (MAUT) for each units of analysis. Therefore, once we calculated the ISA we have also extracted the potential population for each of the categories considered.

\section{Key Words}

Environmental Health - Environmental Health Index - Chaco - Multiattribute Utility Model

Publicado en formato digital: Dra. Lic. Liliana Ramírez y Prof. Romina Claret. LA SALUD AMBIENTAL MEDIDA A PARTIR DE DATOS CENSALES. UNA MIRADA SOBRE EL AREA METROPOLITANA DEL GRAN RESISTENCIA Y PRESIDENCIA ROQUE SAENZ PEÑA. Revista Geográfica Digital. IGUNNE. Facultad de Humanidades. UNNE. Año 11. No 21. Enero - Junio 2014. ISSN 1668-5180 Resistencia, Chaco. En: http://hum.unne.edu.ar/revistas/geoweb/default.htm 


\section{Introducción}

Organismos como la Organización Mundial de la Salud (OMS) y la Organización Panamericana de la Salud (OPS) como máximos referentes, señalan que los riesgos ambientales para la salud incluyen un amplio "espectro de peligros de distinta naturaleza (por ejemplo, física, química, biológica), en diferentes medios (como el agua, el aire, los alimentos o el suelo), en diferentes entornos (como el hogar, la escuela o la comunidad) y con relación a distintas actividades (por ejemplo, el juego o el trabajo). Por ello, uno de los principales objetivos de los indicadores de salud ambiental es contribuir a modelar la evolución de los riesgos ambientales que más afectan a la salud de la población y su distribución espacial, así como definir y propiciar una respuesta -normativa adecuada- y las intervenciones oportunas que permitan reducir esos riesgos" iv. Además, los indicadores de salud ambiental constituyen una herramienta fundamental a la hora de definir grupos de población especialmente vulnerables.

En la última década los cambios producidos en las causas de morbi-mortalidad de la población han definido una alteración en los patrones epidemiológicos que caracterizan a estos aspectos poblacionales. La OMS (2006) sostiene que estas mutaciones dejan entrever una tendencia descendente de las causas infecciosas y parasitarias en general y en oposición se aprecia una mayor participación de las causas relacionadas con los factores endógenos. Esto ha llevado a que los determinantes ambientales en salud ganen participación en la definición del estado sanitario de la población y, por ende, intervengan de forma más relevante en el perfil epidemiológico que caracteriza a la morbi-mortalidad, perfil en el cual la perspectiva territorial es central, ya que desde los inicios de la aparición de la Geografía Médica y de la Geografía de la Salud $^{\mathrm{v}}$ ha sido advertida la relación existente entre salud y ambiente ${ }^{\mathrm{vi}}$.

\section{Antecedentes}

En el año 2000 Meade y Earickson señalaron que la Geografía Médica es una perspectiva antigua y una nueva especialización de la ciencia geográfica; su origen se remonta a Hipócrates quien señalaba que para el estudio de la medicina se deben considerar los efectos de las estaciones del año, la procedencia de los vientos, la procedencia del agua, el tipo de suelo, así como la vida y el estilo de vida de los habitantes (Pringle 1996; Meade y Earickson, 2000). Desde entonces, pensadores y científicos han puesto énfasis en esta perspectiva de la salud como una interacción entre el hombre y el ambiente. ${ }^{\text {vii }}$

Aquello en lo que Hipócrates ponía énfasis para comprender la relación salud-medio aparece en la literatura médica del Siglo XVIII como factores relacionados con la morbilidad de la población. Aunque muchos autores destacaban el carácter causal de los factores atmosféricos, poco a poco se hizo evidente que los procesos morbosos podían ser consecuencia de la interacción entre el hombre y un medio ambiente muy complejo. ${ }^{\text {viii }}$

Seguinot Barbosa, J. (2011) afirma que la Geografía Médica, rama de la Geografía Humana "parte de la premisa de que el ser humano forma parte de agrupaciones sociales amplias. Estas sociedades crean un entorno social y físico mediante procesos de transformación de sus propias estructuras sociales y de la superficie terrestre en la que se asientan. Estas transformaciones se deben a procesos económicos, políticos, culturales y demográficos que culminan influenciando la condición de salud de una población dada". ix

La búsqueda de medidas objetivas del estado de salud de la población es una antigua tradición en salud pública, particularmente en epidemiología. Desde el siglo XIX "la descripción y análisis del estado de salud fueron fundados en medidas de mortalidad y sobrevivencia. Más recientemente, en parte como resultado del control exitoso de las enfermedades infecciosas tradicionalmente responsables de la mayor carga de mortalidad, así como producto de una visión más comprensiva del concepto de salud y sus determinantes poblacionales, se reconoció la

Publicado en formato digital: Dra. Lic. Liliana Ramírez y Prof. Romina Claret. LA SALUD AMBIENTAL MEDIDA A PARTIR DE DATOS CENSALES. UNA MIRADA SOBRE EL AREA METROPOLITANA DEL GRAN RESISTENCIA Y PRESIDENCIA ROQUE SAENZ PEÑA. Revista Geográfica Digital. IGUNNE. Facultad de Humanidades. UNNE. Año 11. № 21. Enero - Junio 2014. ISSN 1668-5180 Resistencia, Chaco. En: http://hum.unne.edu.ar/revistas/geoweb/default.htm 
necesidad de considerar también otras dimensiones del estado de salud. En consecuencia, las medidas de morbilidad, discapacidad y de determinantes no biológicos de la salud, como el acceso a servicios, la calidad de la atención, las condiciones de vida y los factores ambientales son de necesidad creciente para analizar con objetividad la situación de salud de grupos poblacionales y para documentar la capacidad de las personas de funcionar física, emocional y socialmente."”

Urteaga (1980) sostiene que cada vez se hicieron más evidentes para la comunidad médica las conexiones que existen entre la morbilidad, la mortalidad y el ambiente, por lo cual dichas relacionales pasaron a ser objeto de estudio. "Al superar la medicina el estudio del cuerpo humano, como lugar privilegiado de enfermedad, se enfrenta a un espacio mucho más amplio, que primero será sólo físico, para devenir finalmente en social. Los médicos se convertirán así, en una de las primeras comunidades científicas que elaborarán un estudio de espacios concretos, localizados, de regiones; en suma, una Geografía, en el sentido que luego se dio a este término." ${ }^{\mathrm{i}}$

Así como la ciencia geográfica guarda estrecha relación con diferentes disciplinas, en este caso puntual, un campo de estudio estrechamente vinculado a la Geografía Médica o Geografía de la Salud es la Salud Ambiental, orientada -como afirma Seguinot Barbosa (2011)- a la disminución de los efectos nocivos que el ambiente produce en la salud. Bajo esta concepción, el ambiente es entendido como todo lo que es externo al individuo humano ${ }^{\text {xil }}$ es decir, todo lo que puede influir en la condición de salud de la población.

La OMS (2001) afirma que es de la relación salud-ambiente que surge la atención sobre la salud ambiental de la población, ya que se consideran todos los factores ambientales que podrían incidir en la salud y acciona mediante la promoción de la prevención de las enfermedades y la creación de ambientes propicios para la salud, es decir ambientes saludables o ambientes sanos. Así, la salud humana dependerá de la capacidad de la sociedad para mejorar la interacción entre las actividades humanas y el ambiente.

Las relaciones entre la salud humana y las influencias ambientales conllevaron al surgimiento del concepto Salud Ambiental que, acorde con lo expresado por la Organización Mundial de la Salud (1989), "comprende aquellos aspectos de la salud y la enfermedad humanas que son determinados por factores en el ambiente. También se refiere a la teoría y práctica de valorar y controlar factores en el ambiente que estén en posibilidades de afectar la salud." ${ }^{\text {iii }}$

En 1993, tras la cumbre de Río de Janeiro en 1992, se revisa la conceptualización de Salud Ambiental especificando la participación de distintos factores e incorporando las actividades de corrección, control y prevención con relación a los impactos de los factores ambientales determinantes en el ser humano, con lo cual se expone una nueva definición: "la salud ambiental comprende aquellos aspectos de la salud humana incluyendo la calidad de vida, que son determinados por factores físicos, químicos, biológicos, sociales y psicológicos en el medio ambiente. También se refiere a la teoría y práctica de valorar, corregir, controlar y evitar aquellos factores en el medio ambiente que potencialmente puedan perjudicar la salud de generaciones actuales y futuras." ${ }^{\text {iv }}$

Acorde con lo expuesto, es posible afirmar que desde la antigüedad han preocupado las causas, condiciones o circunstancias que determinan el estado de salud, lo que se dio a conocer -a partir de 1970- como determinantes. Marc Lalonde (1973) desarrolló el modelo holístico de Lamfraboise para explicar la producción o pérdida de salud en relación a diversos determinantes y especificó que el nivel de salud de una comunidad estaría influido por cuatro (4) grandes grupos de determinantes tal como se aprecia en la figura 1. Además de identificar cuáles son los determinantes de salud, Marc Lalonde analizó el peso en la mortalidad de cada uno de ellos:

- El estilo de vida (Lifestyle): representa el $43 \%$ del peso en la mortalidad, es decir es un determinante "muy importante en el binomio salud-enfermedad y en los últimos años se ha generado una abundante cantidad de evidencia científica sobre como los comportamientos y

Publicado en formato digital: Dra. Lic. Liliana Ramírez y Prof. Romina Claret. LA SALUD AMBIENTAL MEDIDA A PARTIR DE DATOS CENSALES. UNA MIRADA SOBRE EL AREA METROPOLITANA DEL GRAN RESISTENCIA Y PRESIDENCIA ROQUE SAENZ PEÑA. Revista Geográfica Digital. IGUNNE. Facultad de Humanidades. UNNE. Año 11. No 21. Enero - Junio 2014. ISSN 1668-5180 Resistencia, Chaco. En: http://hum.unne.edu.ar/revistas/geoweb/default.htm 
los hábitos de vida condicionan no sólo la salud, sino la situación sanitaria de las poblaciones y los recursos a ellas destinados." $x \mathrm{v}$

- Biología humana (Human Biology): representa el $27 \%$ del peso en la mortalidad e incluye todos aquellos elementos que producen alteración de la salud como ser la herencia genética, los procesos de crecimiento y maduración, alteraciones bioquímicas, físicas, fisiológicas, anatómicas, inmunitarias, etc., de los diferentes órganos y sistemas del ser vivo.

- Medio ambiente (Environment): representa el $19 \%$ del peso en la mortalidad y se fundamenta en que el hombre no vive aislado, sino inmerso en un ambiente "determinado y expuesto a distintos factores como ser físicos (temperatura, ruidos, radiaciones), químicos (contaminación por plaguicidas, metales pesados), biológicos (presencia de bacterias, virus y otros microorganismos patógenos) y psicológicos, sociales y culturales (como intoxicación, estrés, etc.)." xvi

- Sistema de asistencia sanitaria (Health Care Organization): es el determinante de menor peso en la mortalidad, 11\%; R. Meneu de Guillerna (s/f) sostiene que "la asistencia sanitaria no se limita a identificar (diagnosticar) y resolver (tratar) los problemas de salud de los individuos, sino que también lleva a cabo actuaciones de prevención individuales (como las vacunaciones) y algunos modos de intervención sobre la comunidad".

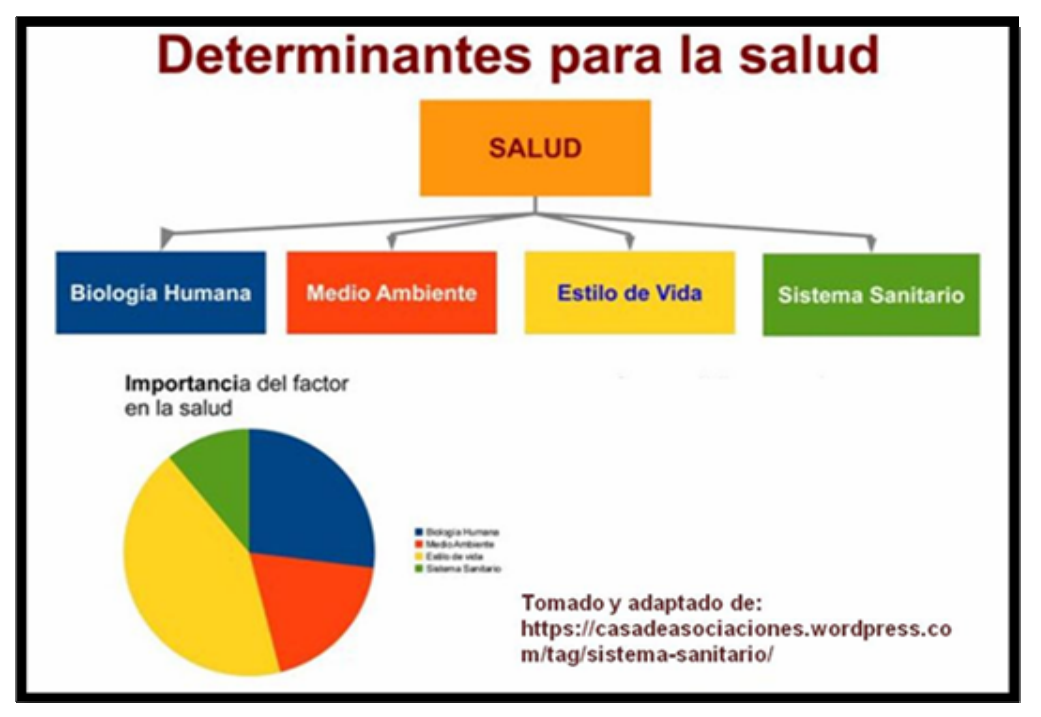

Figura 1: Determinantes para la salud

El progresivo conocimiento sobre las influencias del ambiente en la salud humana ha llevado al desarrollo de procesos de monitoreo a través del uso de distintos indicadores sobre la condición de los distintos componentes del ambiente y la medición de sus efectos en la salud humana $^{\text {xvii }}$ y a los cuales la Organización Panamericana de la Salud (2001) define como una noción de la vigilancia en salud pública que define una medida de la salud o de un factor asociado con la salud en una población especificada.

El monitoreo de la salud ambiental implica considerar los factores determinantes más relevantes a la vinculación entre la salud y el entorno, es decir, que "los indicadores proveen rasgos de asuntos de mayor trascendencia o bien hacen perceptible la tendencia de un fenómeno indetectable de momento"xviii. La Organización Panamericana de la Salud (2001) expresa que los indicadores representan medidas-resumen que capturan información relevante sobre distintos atributos y dimensiones del estado de salud y del desempeño del sistema de salud y que, vistos en conjunto, intentan reflejar la situación sanitaria de una población y sirven para vigilarla. Meneu de Guillerna sostiene que los indicadores de salud, generados de manera

Publicado en formato digital: Dra. Lic. Liliana Ramírez y Prof. Romina Claret. LA SALUD AMBIENTAL MEDIDA A PARTIR DE DATOS CENSALES. UNA MIRADA SOBRE EL AREA METROPOLITANA DEL GRAN RESISTENCIA Y PRESIDENCIA ROQUE SAENZ PEÑA. Revista Geográfica Digital. IGUNNE. Facultad de Humanidades. UNNE. Año 11. No 21. Enero - Junio 2014. ISSN 1668-5180 Resistencia, Chaco. En: http://hum.unne.edu.ar/revistas/geoweb/default.htm 
regular y manejados dentro de un sistema de información dinámico constituyen una herramienta fundamental para los tomadores de decisión en todos los niveles de gestión ya que aportan evidencia sobre el estado y tendencias de la situación de salud en la población.

\section{Determinantes ambientales y su impacto en la salud: indicadores e índices}

Respecto de la aparición y desarrollo de las enfermedades, la exposición a factores ambientales juega un papel muy importante, pudiendo estos ejercer un profundo impacto sobre la salud, en especial de los grupos más vulnerables (niños y ancianos). Según expone la OMS "casi una cuarta parte de la carga mundial de morbilidad y más de un tercio de morbilidad infantil específicamente, son atribuibles a factores ambientales modificables". Agrega, además, que "los factores de riesgo ambiental contribuyen a la carga de morbilidad en 85 categorías de las 102 enfermedades principales que enfrenta hoy el mundo", y que "en el nivel global el porcentaje de muertes atribuibles al ambiente es de $24 \%$ y para los niños de 0 a 14 años esta cifra se eleva al $36 \%$, lo que refleja una carga desproporcionada de morbilidad por esas causas. El número de años de vida sana perdidos por habitante como consecuencia de factores de riesgo ambiental es cerca de 5 veces mayor en los niños de 0 a 5 años que en los adultos. Esta cifra se multiplica por 7 para las enfermedades más significativas, como las diarreicas y respiratorias, la malaria y la malnutrición. En los países en desarrollo esta carga puede llegar a multiplicarse hasta por 8 cuando se analizan las afecciones respiratorias."

En cuanto a los indicadores el abanico de posibilidades para elaborar y abordar se corresponde con la complejidad misma de los distintos espacios geográficos, pero también con la gran disparidad de fuentes de información y el acceso a las mismas. Por otro lado la relación salud-ambiente es tan compleja y dinámica que difícilmente un solo índice pueda detectar esas características. En este sentido la Oficina Europea de la OMS expuso en la $3^{\mathrm{a}}$ Conferencia Ministerial sobre Salud y Medio Ambiente, celebrada en Londres en Junio de 1999 los Planes Nacionales de Acción sobre Salud y Medio Ambiente (NEHAPs) para los cuales "era necesario desarrollar un sistema de información sobre salud y medio ambiente, que permitiera desarrollar la vigilancia de los factores ambientales determinantes de los estados de salud, que sirviera para elaborar una política de acciones y comunicación con el público, y al mismo tiempo posibilitara la comparación a nivel internacional entre los propios Estados Miembros" ${ }^{\prime \prime x}$.

A los fines de esta contribución haremos la distinción conceptual y empírica entre indicador e índice. Respecto del concepto indicador [simple] una de las definiciones más utilizadas por diferentes organismos y autores es la que Bauer dio en 1966: "Los indicadores (...) son estadísticas, serie estadística o cualquier forma de indicación que nos facilita estudiar dónde estamos y hacia dónde nos dirigimos con respecto a determinados objetivos y metas, así como evaluar programas específicos y determinar su impacto", se trata de valores simples por lo general relativos al total del colectivo que les da origen, se utilizan como medidas descriptivas y de diagnóstico de una determinada situación, a la vez que son muy importantes para las comparaciones de un mismo hecho a través del tiempo. Un índice, o indicador compuesto, se formula cuando los indicadores simples se compilan en un valor único, basado en un modelo subyacente del concepto multidimensional que se está intentando medir ${ }^{\text {xxi }}$ (ej.: índice de calidad de vida, índice de calidad ambiental, índice de precios, environmental performance index, índice de competitividad).

En cuanto a los indicadores que se consideran para mediar la Salud Ambiental hemos detectado algunos antecedentes que muestran la elevada complejidad que implica su estudio, a la vez que apreciamos la extrema dificultad de abordar todas sus dimensiones debido a la falta de información, razón por la cual, habrá que contemplar la elaboración de un índice basado en los antecedentes, pero ajustado a la disponibilidad de datos.

En 2002 Yassi y otros autores consideraron que la salud ambiental era posible de ser analizada teniendo en cuenta la naturaleza de los peligros de la salud humana (cuadro 1) y estos peligros se pueden estudiar a la luz de las rutas de exposición (aire, agua, suelo); y a la luz del

Publicado en formato digital: Dra. Lic. Liliana Ramírez y Prof. Romina Claret. LA SALUD AMBIENTAL MEDIDA A PARTIR DE DATOS CENSALES. UNA MIRADA SOBRE EL AREA METROPOLITANA DEL GRAN RESISTENCIA Y PRESIDENCIA ROQUE SAENZ PEÑA. Revista Geográfica Digital. IGUNNE. Facultad de Humanidades. UNNE. Año 11. № 21. Enero - Junio 2014. ISSN 1668-5180 Resistencia, Chaco. En: http://hum.unne.edu.ar/revistas/geoweb/default.htm 
lugar donde ocurren (hogar, el trabajo, la escuela o las comunidades). Este trabajo muy completo centra su interés en las dimensiones de la salud ambiental pero no avanza sobre indicadores concretos.

\begin{tabular}{|ll|}
\hline Peligros tradicionales & Peligros modernos \\
\hline Enfermedades por vectores & Humo del tabaco \\
Agentes infecciosos & Alcohol \\
Viviendas y refugios & Peligros por transporte \\
Agua potable y sanidad & Contaminación ambiental \\
Contaminación del aire interior & Contaminación del aire exterior \\
proveniente de cocinas & proveniente de la industria y \\
& los automóviles \\
Deficiencias dietarias & Uso de sustancias quimicas \\
Reproducción & Peligros ocupacionales \\
Peligros de daño en la agricultura & Dieta desbalanceada \\
\hline
\end{tabular}

Cuadro 1: Naturaleza de los peligros de la salud humana. Peligros tradicionales y modernos para la salud. Tomado de Yassi et al (2002) Salud Ambiental Básica. OMS.

En 2004, Paz y otros autores fueron más explícitos ya que en su trabajo sobre indicadores de salud ambiental señalan las variables que intervienen: aire, radiación, ruido, viviendas e instalaciones (cuadro 2), accidentes de tráfico, agua y saneamiento, seguridad alimentaria (cuadro 3), residuos peligrosos y tierras contaminadas, emergencias químicas y salud laboral (cuadro 4). Los indicadores que forman parte de estas variables se encuadran en el marco conceptual DPSEEA (Fuerzas impulsoras, Presión, Estado - Exposición - Efecto - Acción), que fue desarrollado por la OMS en los años 90, "Indicadores de Salud Medioambientales: Marco y Metodologías" -WHO/SDE/OEH/99.10- (Figura 2).

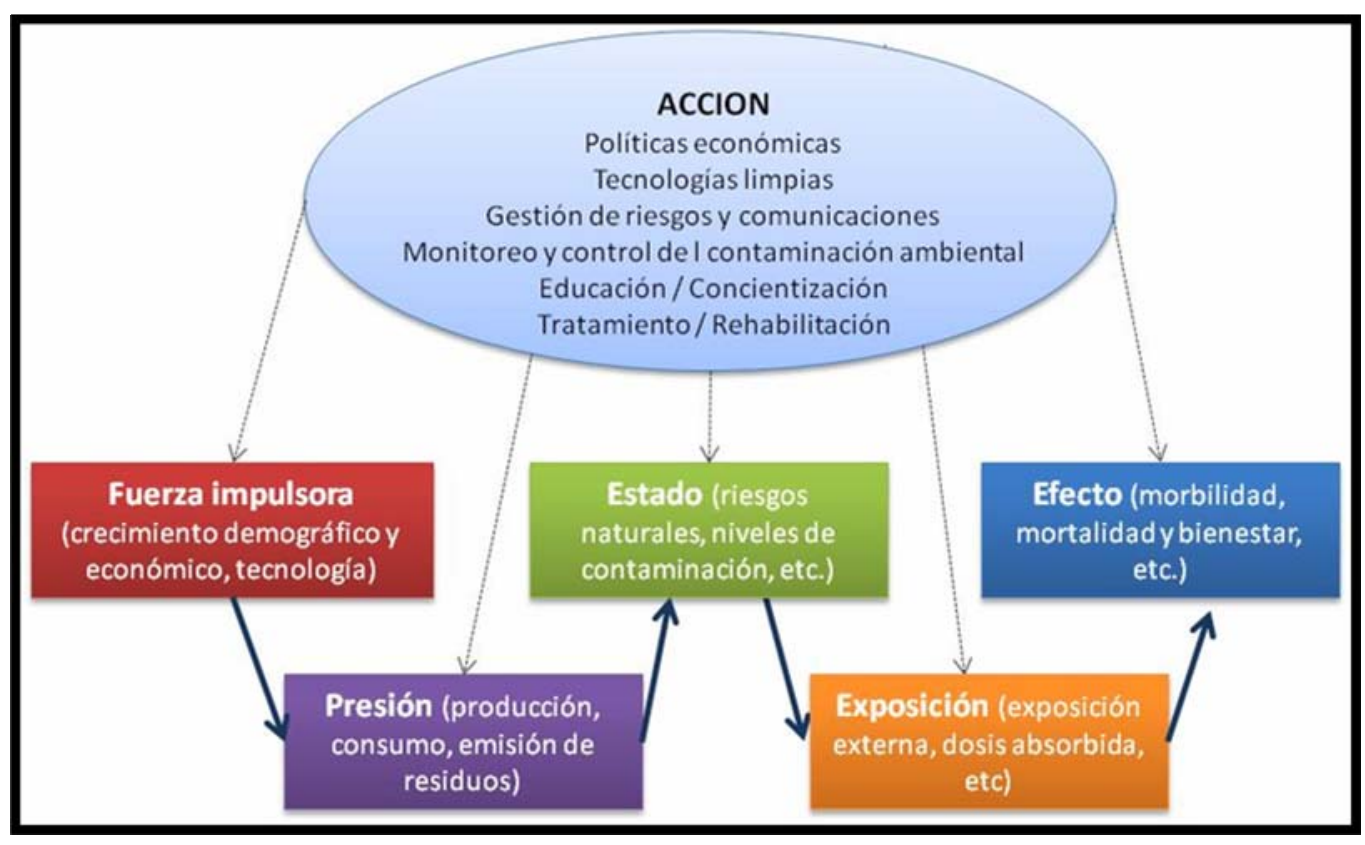

Figura 2: Modelo Fuerzas Impulsoras, Presiones,

Estado, Exposición, Efecto, Acción (DPSEEA) de la OMS.

Publicado en formato digital: Dra. Lic. Liliana Ramírez y Prof. Romina Claret. LA SALUD AMBIENTAL MEDIDA A PARTIR DE DATOS CENSALES. UNA MIRADA SOBRE EL AREA METROPOLITANA DEL GRAN RESISTENCIA Y PRESIDENCIA ROQUE SAENZ PEÑA. Revista Geográfica Digital. IGUNNE. Facultad de Humanidades. UNNE. Año 11. No 21. Enero - Junio 2014. ISSN 1668-5180 Resistencia, Chaco. En: http://hum.unne.edu.ar/revistas/geoweb/default.htm 
Revista Geográfica Digital. IGUNNE. Facultad de Humanidades. UNNE. Año 11. № 21. Enero - Junio 2014. ISSN 1668-5180 Resistencia, Chaco

\begin{tabular}{|l|}
\hline \multicolumn{1}{|c|}{ Nombre del Indicador } \\
\hline \multicolumn{1}{|c|}{} \\
\hline Kilómetros conducidos por tipo de transporte y persona \\
\hline Consumo de gasolina por tipo de transporte \\
\hline Emisiones de contaminantes atmosféricos \\
\hline Concentraciones ambientales de contaminantes atmosféricos \\
\hline Mortalidad infantil por enfermedades respiratorias \\
\hline Mortalidad por enfermedades respiratorias (todas las edades) \\
\hline Mortalidad por enfermedades del sistema circulatorio (todas las edades) \\
\hline Políticas para reducir el humo de tabaco ambiental \\
\hline Radiación \\
\hline \multicolumn{1}{c|}{ Nombre del Indicador } \\
\hline Incidencia de cáncer de piel \\
\hline Monitorización de actividad radioactiva \\
\hline Ruido \\
\hline \\
\hline Molestias por distintos tipos de ruido \\
\hline Trastornos del sueño por ruido \\
\hline Aplicación de los reglamentos, restricciones y medidas de eliminación de ruidos. \\
\hline Vivienda e Instalaciones \\
\hline Superficie habitable por persona \\
\hline Población en viviendas substandard \\
\hline Mortalidad causad por causas externas en niños menores de 5 años \\
\hline Ámbito y aplicación de los reglamentos de edificación de viviendas. \\
\hline Reglamentos d uso del suelo y ordenación del ternitorio \\
\hline \\
\hline
\end{tabular}

Cuadro 2: Indicadores de salud ambiental (1/3)

El sistema de indicadores propuesto por estos autores tuvo que ver con una de las recomendaciones de la $3^{\mathrm{a}}$ Conferencia Ministerial sobre Salud y Medio Ambiente, celebrada en Londres en junio de 1999, en esa ocasión se recomendaba la puesta en práctica de los Planes Nacionales de Acción sobre Salud y Medio Ambiente (NEHAPs). Estos planes implican generar un sistema de información sobre salud y ambiente que permita observar, vigilar o monitorear los factores ambientales determinantes de los estados de salud, sólo así serviría para elaborar políticas de acciones y comunicación con el público, y al mismo tiempo permitir la comparación a nivel internacional.

Nadie duda de la excelente propuesta de los beneficios que su implementación tendría, el inconveniente radica en la imposibilidad de llevar a cabo este sistema debido a la escasa disponibilidad de datos para dar cuenta de la gran mayoría de los indicadores que incluyen.

Publicado en formato digital: Dra. Lic. Liliana Ramírez y Prof. Romina Claret. LA SALUD AMBIENTAL MEDIDA A PARTIR DE DATOS CENSALES. UNA MIRADA SOBRE EL AREA METROPOLITANA DEL GRAN RESISTENCIA Y PRESIDENCIA ROQUE SAENZ PEÑA. Revista Geográfica Digital. IGUNNE. Facultad de Humanidades. UNNE. Año 11. No 21. Enero - Junio 2014. ISSN 1668-5180 Resistencia, Chaco. En: http://hum.unne.edu.ar/revistas/geoweb/default.htm 
Revista Geográfica Digital. IGUNNE. Facultad de Humanidades. UNNE. Año 11. № 21. Enero - Junio 2014. ISSN 1668-5180 Resistencia, Chaco

\begin{tabular}{|l|}
\hline \multicolumn{1}{|c|}{ Accidentes de tráfico } \\
\hline Mortalidad por accidentes de tráfico \\
\hline Heridos por accidentes de tráfico \\
\hline Agua y Saneamiento \\
\hline Nombicador \\
\hline Cobertura de tratamiento de aguas residuales \\
\hline Excedencias de los valores límite de parámetros microbiológicos en aguas de baño \\
\hline Excedencias de los valores límite para parámetros microbiológicos en aguas de consumo \\
\hline Excedencia de los valores límite para parámetros químicos en aguas de consumo \\
\hline Acceso a agua de consumo saludable (de acuerdo con los valores guía de la OMS) \\
\hline Acceso a sanitarios con un sistema de saneamiento adecuado \\
\hline Brotes de enfermedades causadas por contaminación hídrica \\
\hline Morbilidad por diarrea en niños \\
\hline Efectividad de la vigilancia de aguas de baño \\
\hline Seguridad Alimentaria \\
\hline \multicolumn{1}{|c|}{ Nombre del indicador } \\
\hline Monitorización de compuestos químicos en alimentos. Exposición potencial \\
\hline Número de brotes de origen alimentario \\
\hline Incidencia de casos de enfermedad de origen alimentario \\
\hline Políticas de seguridad alimentaria \\
\hline Efectividad de la vigilancia de la seguridad alimentaria \\
\hline \hline
\end{tabular}

Cuadro 3 Indicadores de salud ambiental (2/3)

Publicado en formato digital: Dra. Lic. Liliana Ramírez y Prof. Romina Claret. LA SALUD AMBIENTAL MEDIDA A PARTIR DE DATOS CENSALES. UNA MIRADA SOBRE EL AREA METROPOLITANA DEL GRAN RESISTENCIA Y PRESIDENCIA ROQUE SAENZ PEÑA. Revista Geográfica Digital. IGUNNE. Facultad de Humanidades. UNNE. Año 11. № 21. Enero - Junio 2014. ISSN 1668-5180 Resistencia, Chaco. En: http://hum.unne.edu.ar/revistas/geoweb/default.htm 


\begin{tabular}{|l|}
\hline \multicolumn{1}{|c|}{ Residuos Peligrosos y Tierras Contaminadas } \\
\hline \multicolumn{1}{|c|}{ Nombel indicador } \\
\hline Generación de residuos peligrosos \\
\hline Áreas contaminadas por residuos peligrosos \\
\hline Legislación sobre residuos peligrosos \\
\hline Emergencias Quimicas \\
\hline \\
\hline Instalaciones con gran cantidad de residuos químicos \\
\hline Mortalidad por accidentes químicos \\
\hline Regulaciones sobre ordenación del territorio \\
\hline Registro de incidentes químicos \\
\hline Centros de servicio toxicológico \\
\hline Protocolos de tratamiento de envenenamientos \\
\hline Estado de preparación del gobierno para emergencias químicas \\
\hline Salud Laboral \\
\hline Mortalidad laboral \\
\hline Tasa de enfermedad o accidentes laborales \\
\hline Absentismo laboral por enfermedad \\
\hline Registros sobre enfermedades laborales \\
\hline \multicolumn{1}{|c|}{ Nombre del indicador } \\
\hline
\end{tabular}

Cuadro 4: Indicadores de salud ambiental (3/3)

\section{Objetivos y áreas de estudio}

Sin lugar a dudas todos los antecedentes indicados señalan una preocupación cada vez mayor por intentar dar cuenta de las características de la salud ambiental, sin embargo cada país, cada jurisdicción, tiene sus propias limitaciones para medirla en tanto no se relevan datos suficientes para ello. Dentro de las restricciones que tenemos, en este trabajo nos hemos propuesto:

- Construir un Índice de Salud Ambiental (ISA), a partir de datos censales disponibles, en las dos áreas urbanas más destacadas de la provincia del Chaco: Gran Resistencia (AMGR) y Presidencia Roque Sáenz Peña (PRSP).

- Determinar desigualdades en Salud Ambiental.

- Cuantificar la población según ISA de diferente criticidad.

Como señalamos anteriormente las dos áreas escogidas para el análisis son el AMGR (constituida por 4 municipios: Resistencia, Fontana, Puerto Barranqueras y Puerto Vilelas) y Presidencia Roque Sáenz Peña. En la figura que sigue se muestran ambos espacios seleccionados.

Publicado en formato digital: Dra. Lic. Liliana Ramírez y Prof. Romina Claret. LA SALUD AMBIENTAL MEDIDA A PARTIR DE DATOS CENSALES. UNA MIRADA SOBRE EL AREA METROPOLITANA DEL GRAN RESISTENCIA Y PRESIDENCIA ROQUE SAENZ PEÑA. Revista Geográfica Digital. IGUNNE. Facultad de Humanidades. UNNE. Año 11. No 21. Enero - Junio 2014. ISSN 1668-5180 Resistencia, Chaco. En: http://hum.unne.edu.ar/revistas/geoweb/default.htm 


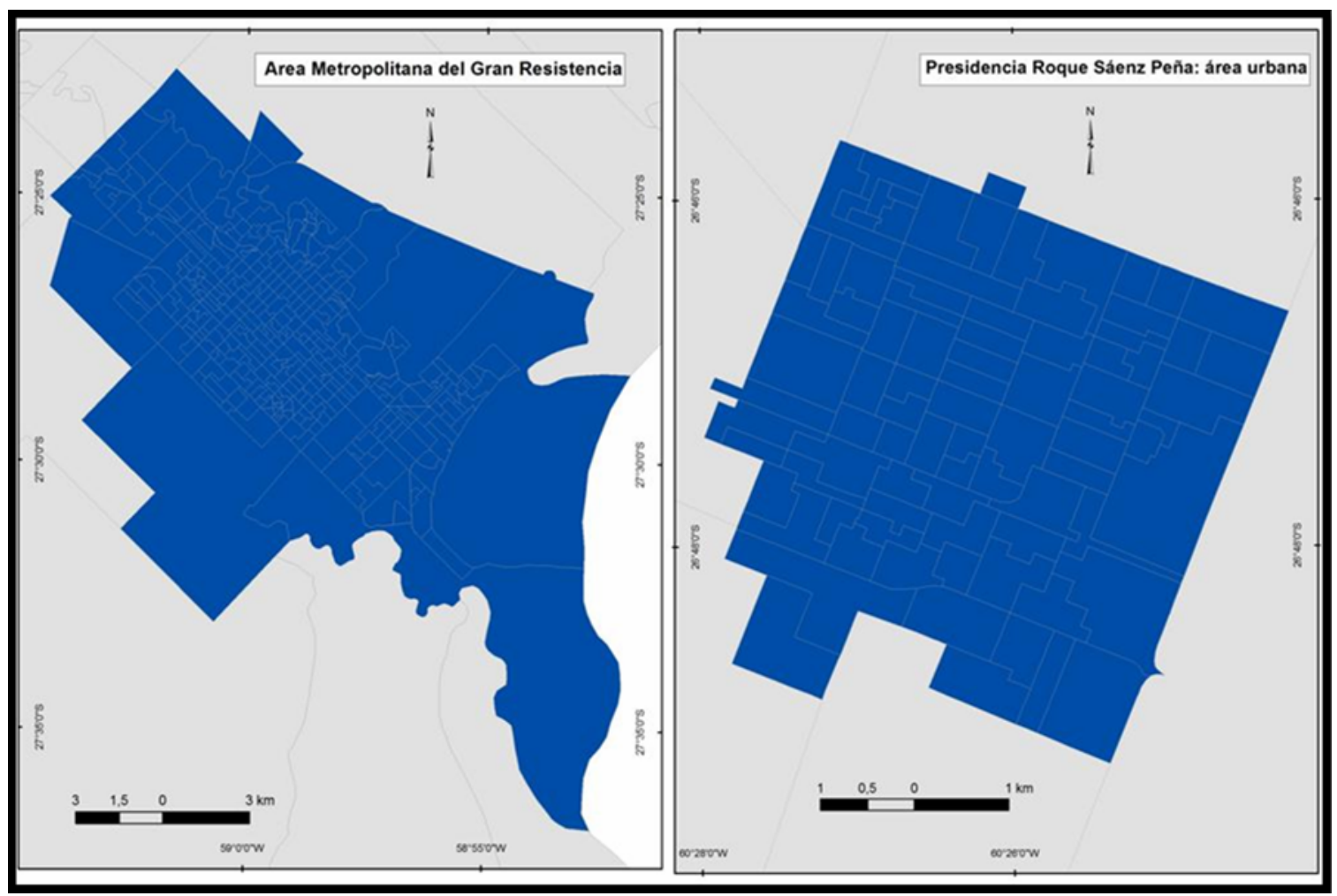

Figura 3: Área Metropolitana del Gran Resistencia y Presidencia Roque Sáenz Peña

El AMGR está conformado por 368 radios censales mientras que PRSP está constituida por 87 radios censales.

\section{Materiales y Metodología}

Los materiales para alcanzar los objetivos propuestos involucran las siguientes fuentes de información:

- Base espacial georreferenciada de la Provincia del Chaco proporcionada por la Dirección Provincial de Estadística y Censos, de esta base se seleccionaron los radios que corresponden a las dos áreas urbanas antes señaladas.

- Censo Nacional de Población, Hogares y Viviendas, INDEC, 2001, procesamiento de datos basado en Redatam+SP.

En cuanto a las etapas metodológicas que llevamos adelante para alcanzar los objetivos indicados anteriormente, las mismas se corresponden a cuatro momentos principales:

- Etapa 1: selección de variables e indicadores constitutivos del ISA considerando la disponibilidad de datos censales pertinentes, procesamiento de datos en Redatam+SP, elaboración de indicadores simples.

Publicado en formato digital: Dra. Lic. Liliana Ramírez y Prof. Romina Claret. LA SALUD AMBIENTAL MEDIDA A PARTIR DE DATOS CENSALES. UNA MIRADA SOBRE EL AREA METROPOLITANA DEL GRAN RESISTENCIA Y PRESIDENCIA ROQUE SAENZ PEÑA. Revista Geográfica Digital. IGUNNE. Facultad de Humanidades. UNNE. Año 11. No 21. Enero - Junio 2014. ISSN 1668-5180 Resistencia, Chaco. En: http://hum.unne.edu.ar/revistas/geoweb/default.htm 
En este momento del trabajo se seleccionaron 11 indicadores que hacen referencia a la vivienda y a los servicios públicos con que cuenta la población. Si consideramos el marco conceptual antes expuesto, entonces sólo daremos cuenta de las condiciones de habitabilidad indicadas a través de la vivienda y las instalaciones y de las características del entorno, consideradas a través de la provisión de agua, el saneamiento, la recolección de residuos, el alumbrado y el pavimento, en definitiva éstos son los servicios públicos con que cuenta la población. De lo dicho se desprende que las variables e indicadores involucrados son:

\begin{tabular}{|l|c|}
\hline \multicolumn{2}{|c|}{ Condiciones vivienda, instalaciones y habitabilidad } \\
\hline \multicolumn{1}{|c|}{ Denominación } & Código \\
\hline $\begin{array}{l}\text { Superficie habitable por persona: } \\
\text { Hacinamiento: Hogares con 3 y más personas por habitación }\end{array}$ & Viv_Ex1 \\
\hline $\begin{array}{l}\text { Viviendas Subestandar } \\
\text { Calidad de los materiales de la Vivienda } \\
\text { CALMAT IV y V (condiciones más deficientes) }\end{array}$ & Viv_Ex2 \\
\hline $\begin{array}{l}\text { Viviendas Subestandar } \\
\text { Pisos de tierra o ladrillo suelo }\end{array}$ & Viv_Ex3 \\
\hline $\begin{array}{l}\text { Viviendas Subestandar } \\
\text { Paredes de cartón, madera paja o material de desecho }\end{array}$ & Viv_Ex4 \\
\hline $\begin{array}{l}\text { Viviendas Subestandar } \\
\text { Techos de chapa cartón, fibrocemento, caña, tabla o paja. }\end{array}$ & Viv_Ex5 \\
\hline $\begin{array}{l}\text { Viviendas Subestandar } \\
\text { Servicio sanitario: inodoro con descarga a cámara séptica o pozo } \\
\text { negro, inodoro sin descara, sin inodoro. }\end{array}$ & Viv_Ex6 \\
\hline
\end{tabular}

\begin{tabular}{|l|l|}
\hline \multicolumn{2}{|c|}{ Servicios Públicos agua, saneamiento } \\
\hline \multicolumn{1}{|c|}{ Denominación } & Código \\
\hline Hogares Sin acceso a agua de red pública & SP_Ex1 \\
\hline Hogares Sin acceso a cloacas & SP_Pr2 \\
\hline
\end{tabular}

\begin{tabular}{|c|c|}
\hline \multicolumn{2}{|c|}{ Indicadores sobre residuos y tierras contaminadas } \\
\hline Denominación & Código \\
\hline Hogares Sin acceso a recolección de residuos sólidos urbanos & SP_Ac1 \\
\hline
\end{tabular}

\begin{tabular}{|l|c|}
\hline \multicolumn{2}{|c|}{ Movilidad y Seguridad } \\
\hline \multicolumn{2}{|c|}{ Denominación } \\
\hline Hogares Sin acceso a pavimento. & SṔdigo \\
\hline Hogares Sin acceso a alumbrado público & SP_Ac3 \\
\hline
\end{tabular}

Cuadro 5: Codificación de los Indicadores de Salud Ambiental

- Etapa 2: Estandarización de los valores de los indicadores, ponderación de variables y elaboración del ISA utilizando un Modelo de Utilidad Multiatributo de tipo aditivo (Sumatoria Lineal). Así se estableció un índice para cada radio censal.

En efecto, si bien todos los indicadores contribuyen a generar externalidades negativas, en su interior presentan importantes diferencias, por ello luego de generar los valores relativos los mismos fueron estandarizados considerando que la utilidad 0 es concordante con el valor menos desfavorable [o más favorable] al evento que se analiza, mientras que el valor 1 representará el valor menos favorable. Así un radio censal que tenga el $100 \%$ de hogares sin acceso a agua por red obtendrá el mayor valor estandarizado, es decir 1.

Publicado en formato digital: Dra. Lic. Liliana Ramírez y Prof. Romina Claret. LA SALUD AMBIENTAL MEDIDA A PARTIR DE DATOS CENSALES. UNA MIRADA SOBRE EL AREA METROPOLITANA DEL GRAN RESISTENCIA Y PRESIDENCIA ROQUE SAENZ PEÑA. Revista Geográfica Digital. IGUNNE. Facultad de Humanidades. UNNE. Año 11. No 21. Enero - Junio 2014. ISSN 1668-5180 Resistencia, Chaco. En: http://hum.unne.edu.ar/revistas/geoweb/default.htm 
Revista Geográfica Digital. IGUNNE. Facultad de Humanidades. UNNE. Año 11. № 21.

Enero - Junio 2014. ISSN 1668-5180 Resistencia, Chaco

Posteriormente se definió, para cada conjunto de variables y luego para cada indicador, la ponderación o peso dentro del modelo de utilidad. En la tabla que sigue se muestra el modelo de utilidad multiatributo (MAUT) empleado.

\begin{tabular}{|c|c|}
\hline Condiciones vivienda, instalaciones y habitabilidad & $0,60 p t s$ \\
\hline $\begin{array}{l}\text { Superficie habitable por persona: } \\
\text { Hacinamiento: Hogares con } 3 \text { y más personas por habitación }\end{array}$ & 0,10 \\
\hline $\begin{array}{l}\text { Viviendas Subestandar } \\
\text { Calidad de los materiales de la Vivienda } \\
\text { CALMAT IV y V (condiciones más deficientes) }\end{array}$ & 0,10 \\
\hline $\begin{array}{l}\text { Viviendas Subestandar } \\
\text { Pisos de tierra o ladrillo suelo }\end{array}$ & 0,10 \\
\hline $\begin{array}{l}\text { Viviendas Subestandar } \\
\text { Paredes de cartón, madera paja o material de desecho }\end{array}$ & 0,10 \\
\hline $\begin{array}{l}\text { Viviendas Subestandar } \\
\text { Techos de chapa cartón, fibrocemento, caña, tabla o paja. }\end{array}$ & 0,10 \\
\hline $\begin{array}{l}\text { Viviendas Subestandar } \\
\text { Servicio sanitario: inodoro con descarga a cámara séptica o pozo negro, } \\
\text { inodoro sin descara, sin inodoro. }\end{array}$ & 0,10 \\
\hline $\begin{array}{c}\text { Servicios Públicos agua, saneamiento, recolección, } \\
\text { pavimento y alumbrado }\end{array}$ & $0,40 p t s$ \\
\hline Hogares Sin acceso a agua de red pública & 0,10 \\
\hline Hogares Sin acceso a cloacas & 0,10 \\
\hline Hogares Sin acceso a recolección de residuos sólidos urbanos & 0,10 \\
\hline Hogares Sin acceso a pavimento. & 0,05 \\
\hline Hogares Sin acceso a alumbrado público & 0,05 \\
\hline
\end{tabular}

Cuadro 6: Ponderación de los Indicadores de Salud Ambiental

Luego de obtener las utilidades ponderadas para cada radio censal se procedió a aplicar una sumatoria lineal y así alcanzamos el ISA.

- Etapa 3: Una vez alcanzado el ISA se aplicaron procedimientos de clustering o agrupamientos para apreciar visualmente los patrones de distribución del ISA en las dos áreas urbanas estudiadas.

- Etapa 4: La última fase consistió en la definición de categorías involucradas y la extracción de la población contenida en cada categoría

\section{Resultados}

Los resultados alcanzados permiten, por un lado, poner a prueba el ISA en dos áreas urbanas con características disímiles esperando contar, en un futuro próximo, con datos más actualizados para validar su construcción y conocer cuál es su dinámica; y, por otro lado, apreciar la territorialización de este índice para visualizar cuáles son los sectores más comprometidos considerando la vivienda, las instalaciones y las condiciones de habitabilidad y el acceso a los servicios públicos.

En cuanto a los indicadores sobre condiciones de vivienda, instalaciones y habitabilidad es importante recordar que el derecho a la vivienda está reconocido en diversos instrumentos internacionales de derechos humanos, se incluye en la Declaración Universal de Derechos Humanos (1948), y la Declaración Americana de Derechos y Deberes del Hombre (1948), estableciendo que la vivienda es la base a partir de la cual pueden ejercerse los derechos a la higiene ambiental y a la salud física y mental ${ }^{x \times i i}$. En este sentido la vivienda es considerada un espacio vital, que debe ser adecuada para poder reducir al mínimo las enfermedades transmisibles. "La carencia y las deficiencias en la vivienda y la falta de saneamiento constituyen

Publicado en formato digital: Dra. Lic. Liliana Ramírez y Prof. Romina Claret. LA SALUD AMBIENTAL MEDIDA A PARTIR DE DATOS CENSALES. UNA MIRADA SOBRE EL AREA METROPOLITANA DEL GRAN RESISTENCIA Y PRESIDENCIA ROQUE SAENZ PEÑA. Revista Geográfica Digital. IGUNNE. Facultad de Humanidades. UNNE. Año 11. No 21. Enero - Junio 2014. ISSN 1668-5180 Resistencia, Chaco. En: http://hum.unne.edu.ar/revistas/geoweb/default.htm 
un determinante reiterado del exceso de mortalidad y una característica sistemáticamente vinculada a los niveles de pobreza, el rezago socioeconómico y la inequidad territorial (OPS/OMS: Salud en las Américas, 1998)." xxiii

En cuanto a los indicadores de agua y saneamiento, se señala que las aguas servidas involucran materias orgánicas e inorgánicas, sustancias tóxicas y microorganismos patógenos, de allí que los desechos humanos sin un tratamiento apropiado presentan un peligro de infección parasitaria, hepatitis y varias enfermedades gastrointestinales, incluyendo el cólera, entre otras. En 2002, la OMS estimó que "el 88 \% de todos los casos globales de diarrea son atribuibles al agua insegura y a la contaminación de los alimentos, así como también a falta de infraestructura sanitaria adecuada y a comportamientos de higiene deficientes. Sobre la base de estudios publicados por la Sociedad Argentina de Pediatría (SAP), puede considerarse que el $100 \%$ de la carga de infecciones intestinales parasitarias son atribuibles al ambiente, y son consecuencia de la falta de un manejo adecuado de las excretas, deficiente provisión de agua potable y malas prácticas de higiene."

La recolección de residuos sólidos urbanos (RSU) es cada vez más necesaria ya que los depósitos a cielo abierto o los micro-basurales representan focos constantes de contaminación y de riesgo sanitario. Estos albergan toda clase de residuos, inclusive peligrosos y patogénicos, que son arrojados sin ningún control ni tratamiento previo, con las consecuencias y riesgos que ello representa para la salud de la población y el cuidado del ambiente. Entre sus consecuencias pueden enumerarse la contaminación del suelos, aire y agua (subterránea y superficial), la presencia de animales transmisores de enfermedades (los más comunes son las moscas, alacranes, escorpiones, pulgas, chinches, ratas y gusanos) a lo que se suman los efectos adversos derivados de la quema incontrolada, deliberada o espontánea de la basura.

Por todo lo expuesto y como una forma que nos permitirá identificar lugares que merecen mayor atención para elaborar acciones focalizadas, y encaminarnos así hacia la equidad territorial, es que desarrollamos esta forma de "mirar" las particularidades de cada radio censal. En efecto, el ISA, puede alcanzar en la peor de las situaciones un valor de 1 punto, ya que se ha elaborado con 11 indicadores pero la sumatoria de las ponderaciones alcanza a 1. Para tener un panorama general podemos señalar que en la provincia del Chaco el valor más elevado es de 0,87 y el promedio es de 0,40. En el AMGR el mayor índice alcanza 0,66 y en PRSP, 0,47, de modo que como primera conclusión podemos expresar que en ambas áreas urbanas el valor máximo alcanzado es inferior al de la provincia; en cuanto a la media es de 0,18 para el AMGR y en PRSP alcanza a 0,21, en este caso también el índice logrado está por debajo del promedio provincial. Esta realidad puede considerarse razonable ya que en áreas urbanas el acceso a los servicios públicos es más aceptable que en áreas rurales y esta situación trabaja a favor del índice construido.

Las desigualdades al interior de cada espacio urbano nos permiten identificar las áreas de mayor criticidad. Si bien para cada uno de los indicadores involucrados en el ISA se ha logrado su propia representación cartográfica, aquí sólo se mostrarán los documentos cartográficos de síntesis, es decir aquellos documentos que muestran el resultado de la aplicación del Modelo de Utilidad Multiatributo, distinguiendo las categorías de los extremos del conjunto, es decir las áreas que se caracterizan por tener situaciones más y menos críticas, y que a la vez definen áreas o sectores homogéneos hacia su interior.

En la figura 4 que muestra la representación del ISA para los radios que conforman el espacio urbano del AMGR, podemos distinguir un patrón de distribución que se corresponde con tres sectores bastante definidos: (*)un área interna o céntrica con las condiciones menos críticas que se localiza alrededor de la plaza central del damero original y se extiende a través de las cuatro avenidas principales con mayor desplazamiento en el sentido noroeste-sudeste, estas condiciones se repiten en ciertos enclaves que se corresponden con barrios planificados [en el oeste, sureste y sur]; (**) un área periférica, que es envolvente, en donde las condiciones referidas a la salud ambiental, por el valor del índice calculado, son críticas, en este sentido

Publicado en formato digital: Dra. Lic. Liliana Ramírez y Prof. Romina Claret. LA SALUD AMBIENTAL MEDIDA A PARTIR DE DATOS CENSALES. UNA MIRADA SOBRE EL AREA METROPOLITANA DEL GRAN RESISTENCIA Y PRESIDENCIA ROQUE SAENZ PEÑA. Revista Geográfica Digital. IGUNNE. Facultad de Humanidades. UNNE. Año 11. No 21. Enero - Junio 2014. ISSN 1668-5180 Resistencia, Chaco. En: http://hum.unne.edu.ar/revistas/geoweb/default.htm 
vemos en la representación la distribución espacial continua y homogénea del índice en casi la totalidad de los radios censales exteriores; $\left({ }^{* \star *}\right)$ finalmente, entre los dos primeros sectores un área de transición en la que los valores alcanzados por el índice no son elevados, razón por la cual podemos afirmar que es un área en la que hay una alta variabilidad de situaciones referidas a la habitabilidad de las viviendas y al acceso a los servicios públicos, por ello, seguramente en este sector y con un análisis de mayor detalle podrán descubrirse otras áreas o sectores que merezcan ser atendidos. En definitiva, y en virtud de los objetivos que marcamos para este aporte, es evidente que en el área periférica la escasa presencia de viviendas con adecuadas condiciones de habitabilidad, el insuficiente acceso a agua por red, la exigua extensión de la red de cloacas, la poca extensión del pavimento y el alumbrado público y la inadecuada recolección de residuos, determina la existencia de la corona externa de la ciudad que marca el sector más crítico de este ISA.

Nuestro propósito también es el de caracterizar el colectivo de población que se encuentra contenido en el sector más crítico; así, por un lado, el ISA nos permite hacer visibles los sitios más vulnerables y, por otro lado, su localización precisa nos permite describir la población que habita en ellos. En primer lugar, según los datos del Censo 2001, en los sitios con mayor ISA residía alrededor del $7,8 \%$ de la población total del AMGR, con un pequeño predomino de los varones respecto de las mujeres (ver cuadro 7).

En cuanto a la composición por edad, en el cuadro 8, podemos apreciar que si bien hay una mayoría de adultos que superan la mitad del colectivo involucrado, más del $40 \%$ son niños de hasta 14 años, esta situación genera una grupo de población vulnerable y en riesgo sanitario en cuanto a patologías que se asocian al ambiente y al entorno inmediato.

Si al dato anterior añadimos que más del $80 \%$ del grupo de población que vive en éstas áreas críticas no disponían de obra social, plan médico o mutual y su única posibilidad de asistencia sanitaria es el servicio público, entonces podemos señalar el riesgo crece, ya que la disponibilidad de servicios con que cuentan los centros de atención primaria de la salud no suelen cubrir todas las necesidades sanitarias de la población (cuadro 9).

\begin{tabular}{|l|l|l|}
\hline Población Total AMGR & $\mathbf{3 5 9 7 1 6}$ & $\mathbf{1 0 0 \%}$ \\
\hline $\begin{array}{l}\text { Población Total área con } \\
\text { mayor valor ISA }\end{array}$ & 28068 & $7,80 \%$ \\
\hline Varones & 14563 & $51,88 \%$ \\
\hline Mujeres & 13505 & $48,12 \%$ \\
\hline
\end{tabular}

Cuadro 7: Población total, varones y mujeres

\begin{tabular}{|l|l|l|}
\hline $\begin{array}{l}\text { Población Total área con } \\
\text { mayor valor ISA }\end{array}$ & $\mathbf{2 8 0 6 8}$ & $\mathbf{7 , 8 0 \%}$ \\
\hline Niños & 12171 & $43,36 \%$ \\
\hline Adultos & 15106 & $53,82 \%$ \\
\hline Adultos Mayores y Ancianos & 791 & $2,82 \%$ \\
\hline
\end{tabular}

Cuadro 8: Población total, niños, adultos y ancianos

\begin{tabular}{|l|l|l|}
\hline $\begin{array}{l}\text { Población Total área con } \\
\text { mayor valor ISA }\end{array}$ & $\mathbf{2 8 4 1 5}$ & $\mathbf{7 , 8 0 \%}$ \\
\hline Con Obra Social & 4736 & $16,87 \%$ \\
\hline Sin Obra Social & 23332 & $83,13 \%$ \\
\hline
\end{tabular}

Cuadro 9: Población total, con y sin obra social

Publicado en formato digital: Dra. Lic. Liliana Ramírez y Prof. Romina Claret. LA SALUD AMBIENTAL MEDIDA A PARTIR DE DATOS CENSALES. UNA MIRADA SOBRE EL AREA METROPOLITANA DEL GRAN RESISTENCIA Y PRESIDENCIA ROQUE SAENZ PEÑA. Revista Geográfica Digital. IGUNNE. Facultad de Humanidades. UNNE. Año 11. No 21. Enero - Junio 2014. ISSN 1668-5180 Resistencia, Chaco. En: http://hum.unne.edu.ar/revistas/geoweb/default.htm 


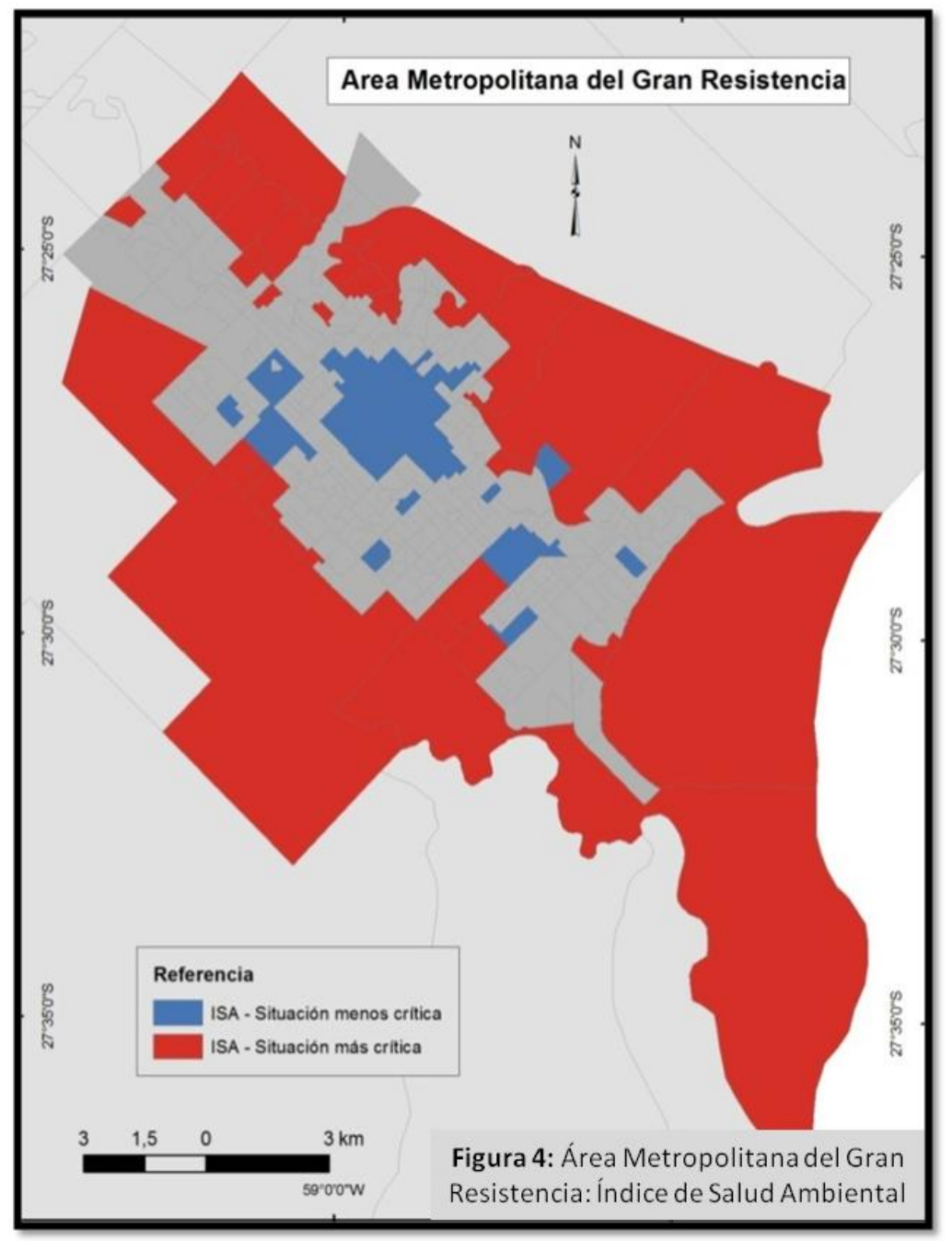

En Presidencia Roque Sáenz Peña, el patrón de distribución del ISA se repite para el caso de las áreas menos críticas, como vemos en la figura 5 un conglomerado o agrupamiento destaca en el sector céntrico de la ciudad y aparecen algunos apéndices o enclaves hacia la corona exterior en coincidencia con barrios planificados. Las áreas que se manifiestan como más críticas se ubican en el área más periurbana en el sector de contacto con el área menos urbanizada y con radios que tienen características de ruralidad.

Publicado en formato digital: Dra. Lic. Liliana Ramírez y Prof. Romina Claret. LA SALUD AMBIENTAL MEDIDA A PARTIR DE DATOS CENSALES. UNA MIRADA SOBRE EL AREA METROPOLITANA DEL GRAN RESISTENCIA Y PRESIDENCIA ROQUE SAENZ PEÑA. Revista Geográfica Digital. IGUNNE. Facultad de Humanidades. UNNE. Año 11. No 21. Enero - Junio 2014. ISSN 1668-5180 Resistencia, Chaco. En: http://hum.unne.edu.ar/revistas/geoweb/default.htm 


\begin{tabular}{|l|c|l|}
\hline Población Total PRSP & $\mathbf{7 5 7 6 1}$ & $\mathbf{1 0 0 \%}$ \\
\hline $\begin{array}{l}\text { Población Total área con } \\
\text { mayor valor ISA }\end{array}$ & 9780 & $12,91 \%$ \\
\hline Varones & 4950 & $50,61 \%$ \\
\hline Mujeres & 4830 & $49,39 \%$ \\
\hline
\end{tabular}

Cuadro 10: Población total, varones y mujeres

\begin{tabular}{|l|c|l|}
\hline $\begin{array}{l}\text { Población Total área con } \\
\text { mayor valor ISA }\end{array}$ & 9780 & $12,91 \%$ \\
\hline Niños & 4326 & $44,23 \%$ \\
\hline Adultos & 5147 & $52,63 \%$ \\
\hline Adultos Mayores y Ancianos & 307 & $3,14 \%$ \\
\hline
\end{tabular}

Cuadro 11: Población total, niños, adultos y ancianos

\begin{tabular}{|l|c|c|}
\hline $\begin{array}{l}\text { Población Total área con } \\
\text { mayor valor ISA }\end{array}$ & 9780 & $12,91 \%$ \\
\hline Con Obra Social & 1402 & $14,34 \%$ \\
\hline Sin Obra Social & 8378 & $85,66 \%$ \\
\hline
\end{tabular}

Una diferencia con el AMGR es que aquí no se advierte continuidad en el área periférica, es decir que las situaciones críticas se encuentran con una localización más precisa; hacia el oeste un radio censal y hacia el este una presencia más destacada en varios radios censales.

En cuanto a la población que se localiza en este sector con un ISA más crítico, la proporción alcanza al $12,91 \%$ del total de la ciudad, este valor es mayor que en el caso del AMGR, pero se asemejan en la paridad entre varones y mujeres (cuadro 10).

También existe una gran semejanza en cuanto a la distribución de la población por grupos de edad, si bien los adultos representan más del 50\%, el grupo de niños registra un valor muy alto -superior al 44\%-dejando a este grupo ante situaciones de vulnerabilidad y riesgo sanitario provocados por la deficiente habitabilidad de las viviendas y el insuficiente acceso a los servicios públicos (cuadro 11).

Finalmente más del $85 \%$ de la población que residía en los sectores más críticos, no poseía obra social, plan médico o mutual, esto también es similar a lo que sucede en el AMGR (cuadro 12). Todo lo señalado nos permite afirmar que la situación que se presentaba en ambas ciudades en 2001 registraba una alta analogía.

Publicado en formato digital: Dra. Lic. Liliana Ramírez y Prof. Romina Claret. LA SALUD AMBIENTAL MEDIDA A PARTIR DE DATOS CENSALES. UNA MIRADA SOBRE EL AREA METROPOLITANA DEL GRAN RESISTENCIA Y PRESIDENCIA ROQUE SAENZ PEÑA. Revista Geográfica Digital. IGUNNE. Facultad de Humanidades. UNNE. Año 11. No 21. Enero - Junio 2014. ISSN 1668-5180 Resistencia, Chaco. En: http://hum.unne.edu.ar/revistas/geoweb/default.htm 


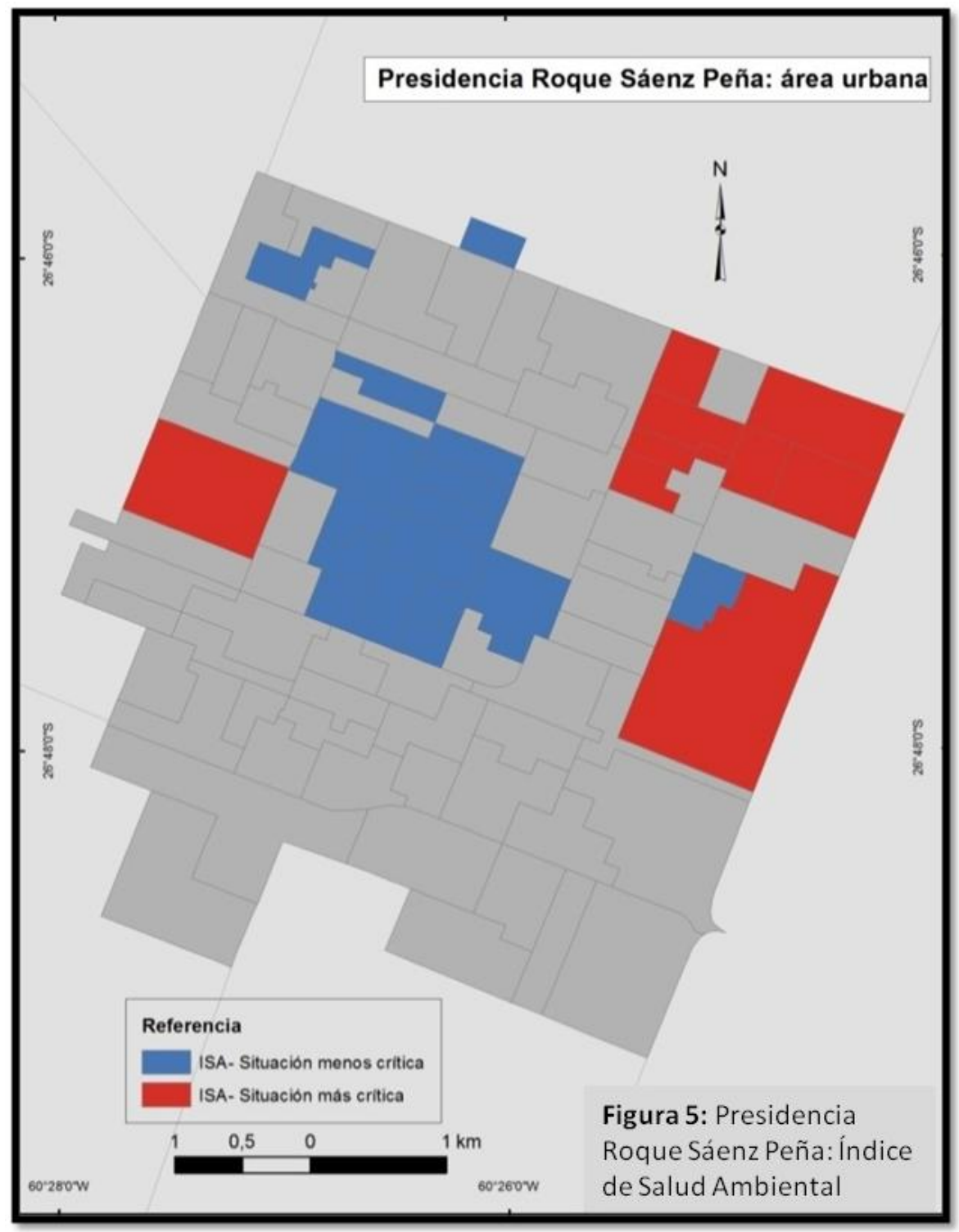

\section{Conclusiones}

Actualmente las administraciones necesitan contar con información que, entre otras propiedades, sea pertinente, actualizada y comparable. EI ISA aquí desarrollado ha sido elaborado con la expectativa de que alcance estas propiedades, sabemos que son muchas las variables ausentes, pero ello se corresponde con la no disponibilidad de datos o fuentes de información que los generan. La continuidad de esta contribución tiene que ver con estas ausencias así, por ejemplo, se espera llevar adelante el relevamiento de otro tipo de información que complemente la que aquí se ha expuesto y que permita ajustar el ISA. Por ejemplo la localización de equipamientos que presenten externalidades positivas o negativas para la salud de la población (por ejemplo, espacios verdes, estaciones de servicios, centros de salud o antenas de telefonía móvil, entre otros) y la actualización de datos para un momento más actual cuando sea posible acceder a la base 2010. Por otro lado, a fin de conocer cuál de las variables tiene el mayor peso y a partir de ella cuáles le siguen en importancia se prevé la realización de

Publicado en formato digital: Dra. Lic. Liliana Ramírez y Prof. Romina Claret. LA SALUD AMBIENTAL MEDIDA A PARTIR DE DATOS CENSALES. UNA MIRADA SOBRE EL AREA METROPOLITANA DEL GRAN RESISTENCIA Y PRESIDENCIA ROQUE SAENZ PEÑA. Revista Geográfica Digital. IGUNNE. Facultad de Humanidades. UNNE. Año 11. № 21. Enero - Junio 2014. ISSN 1668-5180 Resistencia, Chaco. En: http://hum.unne.edu.ar/revistas/geoweb/default.htm 
entrevistas a referentes de la temática y de acuerdo con su experiencia definir la prioridad, de esta forma será posible ponderar el valor de la variable por su peso y realizar un modelo de utilidad multiatributo aditivo ponderado que permita ajustar aún más al ISA. Creemos que resulta una metodología válida toda vez que sea posible actualizar datos y comparar los resultados con otros espacios que permitan dejar al descubierto las desigualdades socio-territoriales y de esta forma auxiliar en la tomas de decisiones de una forma más justa y equitativa.

En cuanto a los resultados, la coincidencia que se ha apreciado tras la aplicación del ISA en el AMGR y en PRSP nos ha permitido validar la propuesta, hacer visible los sitios más críticos o comprometidos desde la mirada de la salud ambiental y conocer con precisión la cantidad y las características de la población más expuesta a situaciones de vulnerabilidad sanitaria. Nuestra experiencia y la mirada sobre contribuciones semejantes nos permiten no dudar de que estos aportes puedan ayudar significativamente a elaborar acciones y propuestas de intervención territorial, para ello es preciso contar con datos actualizados, una limitación que, por el momento, parece difícil de superar.

Publicado en formato digital: Dra. Lic. Liliana Ramírez y Prof. Romina Claret. LA SALUD AMBIENTAL MEDIDA A PARTIR DE DATOS CENSALES. UNA MIRADA SOBRE EL AREA METROPOLITANA DEL GRAN RESISTENCIA Y PRESIDENCIA ROQUE SAENZ PEÑA. Revista Geográfica Digital. IGUNNE. Facultad de Humanidades. UNNE. Año 11. No 21. Enero - Junio 2014. ISSN 1668-5180 Resistencia, Chaco. En: http://hum.unne.edu.ar/revistas/geoweb/default.htm 
Bibliografía

Benítez, María Andrea (2005) Desigualdad, Protesta social y Segregación espacial. El caso de la ciudad de Resistencia, Chaco (Arg). Instituto de Investigación y Desarrollo de la Vivienda (IIDVI). Facultad de Arquitectura y Urbanismo. Universidad Nacional del Nordeste. Pp.03-08

BVSDE. Vivienda Saludable: Sobre la Iniciativa Vivienda. Red Interamericana de Vivienda Saludable (RED VIVSSALUD) Sitio web oficial http://www.bvsde.paho.org/bvsasv/e/iniciativa/quees.html

Den Draak, Maaike (2005) An introduction to medical and health geography. Faculty of Spatial Sciences of the University of Groningen. Population Research Centre. Working Paper Series 051. Pp.02-05.

Gosselin, Pierre - Furgal, Chris - Ruiz, Alfonso (2001). Indicadores básicos de Salud pública ambiental propuestos para la región de la frontera México-Estados Unidos. Grupo de Trabajo de Salud Ambiental del Programa Frontera XXI México-Estados Unidos. Pp.02-12

INDEC (2003) Habitat y vivienda por medio de datos censales. Calidad de los materiales de la vivienda. Pp.03. Disponible en http://www.iaiva.com.ar/INDECdoc13.pdff

Iñiguez Rojas, Luisa (1998) Geografía y Salud: temas y perspectivas en América Latina. Cad. Saúde Pública, Rio de Janeiro. Pp.01-11 y Revista Cubana Salud Pública 2003;29(4)

Meneu de Guillerna, Ricard (s/f) Interculturalidad y extensión de la cobertura de la protección social en salud para trabajadores agrícolas y pueblos originarios. Modulo III: conceptos básicos de salud. Instituto de formación online. Pp.10-20. Disponible en http://biblioteca.programaeurosocial.eu/PDF/Salud/Modulo3.pdf

Ministerio de Sanidad, Servicios Sociales e Igualdad. Indicadores de Salud Ambiental: una propuesta de la Oficina Europea de la OMS para su región. Sitio web oficial http://www.msc.es/en/ciudadanos/saludAmbLaboral/medioAmbiente/indAmbientales.htm

Organización Mundial de la Salud (2001) Boletín Epidemiológico. Vol. 22, N4. Pp. 01-16

Organización Mundial de la salud (2004) Indicadores de Salud Ambiental. Pp. 01-07

Organización Mundial de la Salud (2006) Ambientes Saludables y Prevención De Enfermedades, Hacia una estimación de la carga de morbilidad atribuible al medio ambiente. Pp.04-12

Organización Panamericana de la Salud (2001) Boletín Epidemiológico. Indicadores de Salud: elementos básicos para el análisis de la situación de salud. Pp. 04-10. Disponible en http://www.who.int/ceh/indicators/indicadores.pdf

Organización Panamericana de la Salud (s/f) Indicadores de Salud Ambiental Infantil. Implementación de una iniciativa lanzada en la Cumbre Mundial sobre el Desarrollo Sostenible. Pp.10

MINSAL (2007) Perfil SANA. Capitulo 2: Salud infantil y ambiente. Ministerio de Salud. Argentina. Pp.05-15. Disponible en http://www.msal.gov.ar/promin/publicaciones/pdf/2-capitulodos-sana.pdff

Seguinot Barbosa, J. (2011) Geografía médica y de la salud: conceptos, paradigmas y visiones en el contexto del cambio climático. Departamento de Salud Ambiental. Recinto de Ciencias Médicas. Universidad de Puerto Rico. Pp. 01-05

Urteaga, Luis (1980) Miseria, miasmas y microbios. Las topografías médicas y el estudio del medio ambiente en el siglo XIX. En Cuadernos Críticos de Geografía Humana. Año 5. Número 29. Universidad de Barcelona. Disponible en http://www.ub.edu/geocrit/sv-58.htm

Urteaga, Luis (1993) La teoría de los climas y los orígenes del ambientalismo. En Geo Crítica, $\mathrm{n}^{\circ}$ 99. Disponible en http://divulgameteo.es/uploads/Teor\%C3\%ADa-climas-Ambientalismo.pdf

Publicado en formato digital: Dra. Lic. Liliana Ramírez y Prof. Romina Claret. LA SALUD AMBIENTAL MEDIDA A PARTIR DE DATOS CENSALES. UNA MIRADA SOBRE EL AREA METROPOLITANA DEL GRAN RESISTENCIA Y PRESIDENCIA ROQUE SAENZ PEÑA. Revista Geográfica Digital. IGUNNE. Facultad de Humanidades. UNNE. Año 11. No 21. Enero - Junio 2014. ISSN 1668-5180 Resistencia, Chaco. En: http://hum.unne.edu.ar/revistas/geoweb/default.htm 
Yassi, Annalle -Kjellström, Tord -de Kok, Theo -Guidottu, Tee L. (2002) "Salud Ambiental Básica" Instituto Nacional de higiene, epidemiología microbiología. Ministerio de Salud Pública de Cuba. Instituto Nacional de Higiene, Epidemiología y Microbiología. Ministerio de Salud Pública de Cuba. Pp. 09-16

Ministerio de Sanidad, Servicios Sociales e Igualdad. Indicadores de Salud Ambiental: una propuesta de la Oficina Europea de la OMS para su región. Disponible en http://www.msc.es/en/ciudadanos/saludAmbLaboral/medioAmbiente/indAmbientales.htm

Bauer R. (1966) (Ed.). Social Indicators, Cambridge, MTI, Press.

\footnotetext{
${ }^{\mathrm{i}}$ Constitución Argentina, 1994

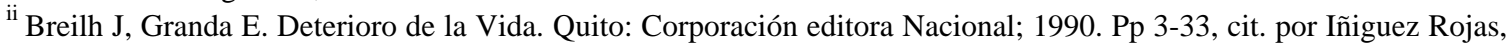
Geografía y Salud: temas y perspectivas en América Latina. Rev Cubana Salud Pública 2003;29(4)

iii Gosselin, Pierre - Furgal, Chris - Ruiz, Alfonso (2001). Indicadores básicos de Salud pública ambiental propuestos para la región de la frontera México-Estados Unidos. Grupo de Trabajo de Salud Ambiental del Programa Frontera XXI México-Estados Unidos. Pp.12

iv Organización Panamericana de la Salud (s/f). Indicadores de Salud Ambiental Infantil. Implementación de una iniciativa lanzada en la Cumbre Mundial sobre el Desarrollo Sostenible. Pp.10

${ }^{\vee}$ Actualmente es posible hacer una diferenciación entre Geografía Médica y Geografía de la Salud. Mientras la primera pone el énfasis en mostrar la distribución espacial de los estados mórbidos, la segunda intenta mostrar la distribución de los factores, determinantes y servicios relacionados con los estados sanitarios de la población.

vi Organización Panamericana de la Salud (2006). "Ambientes Saludables y Prevención De Enfermedades, Hacia una estimación de la carga de morbilidad atribuible al medio ambiente.” Pp. 04-12

vii Den Draak, Maaike (2005) An introduction to medical and health geography. Faculty of Spatial Sciences of the University of Groningen. Population Research Centre. Working Paper Series 05-1. Pp.03

viii Urteaga, Luis (1993) La teoría de los climas y los orígenes del ambientalismo. En Geo Crítica, nº 99. Pp.09

ix Seguinot Barbosa, J. (2011) Geografía médica y de la salud: conceptos, paradigmas y visiones en el contexto del cambio climático. Departamento de Salud Ambiental. Recinto de Ciencias Médicas. Universidad de Puerto Rico. Pp.01 ${ }^{x}$ Organización Mundial de la Salud (2001) Boletín Epidemiológico. Vol. 22, $N^{\circ}$ 4. Pp. 01

xi Urteaga, Luis (1980) Miseria, miasmas y microbios. Las topografías médicas y el estudio del medio ambiente en el siglo XIX. En Cuadernos Críticos de Geografía Humana. Año 5. Número 29. Universidad de Barcelona.

xii Seguinot Barbosa, J. (2011) Geografía médica y de la salud: conceptos, paradigmas y visiones en el contexto del cambio climático. Departamento de Salud Ambiental. Recinto de Ciencias Médicas. Universidad de Puerto Rico. Pp.03

xiii Gosselin, Pierre - Furgal, Chris - Ruiz, Alfonso (2001). Indicadores básicos de Salud pública ambiental propuestos para la región de la frontera México-Estados Unidos. Grupo de Trabajo de Salud Ambiental del Programa Frontera XXI México-Estados Unidos. Pp.11

xiv Gosselin, Pierre - Furgal, Chris - Ruiz, Alfonso Ibídem Pp.03

${ }^{x v}$ Meneu de Guillerna, Ricard (s/f) Interculturalidad y extensión de la cobertura de la protección social en salud para trabajadores agrícolas y pueblos originarios. Modulo III: conceptos básicos de salud. Instituto de formación online. Pp 11

xvi Ibídem Pp.10

xvii Gosselin, Pierre - Furgal, Chris - Ruiz, Alfonso (2001). Indicadores básicos de Salud pública ambiental propuestos para la región de la frontera México-Estados Unidos. Grupo de Trabajo de Salud Ambiental del Programa Frontera XXI México-Estados Unidos. Pp. 02

xviii Gosselin, Pierre - Furgal, Chris - Ruiz, Alfonso (2001). Indicadores básicos de Salud pública ambiental propuestos para la región de la frontera México-Estados Unidos. Grupo de Trabajo de Salud Ambiental del Programa Frontera XXI México-Estados Unidos. Pp. 12

${ }^{x i x}$ MINSAL (2007) Perfil SANA. Capitulo 2: Salud infantil y ambiente. Ministerio de Salud. Pp. 03-04

${ }^{\mathrm{xx}}$ Ministerio de Sanidad, Servicios Sociales e Igualdad. Indicadores de Salud Ambiental: una propuesta de la Oficina Europea de la OMS para su región. Sitio web oficial

xxi Tomado de http://www.colombiassh.org/gtmi/wiki/index.php/Indicador_Compuesto (10/05/2014)

xxii INDEC (2003) Hábitat y vivienda por medio de datos censales. Calidad de los materiales de la vivienda. Pp. 03

xxiii Citado en BVSDE. Vivienda Saludable: Sobre la Iniciativa Vivienda. Red Interamericana de Vivienda Saludable (RED VIVSSALUD). Sitio web oficial.

${ }^{x x i v}$ MINSAL (2007) Perfil SANA. Capitulo 2: Salud infantil y ambiente. Ministerio de Salud. Pp. 05
}

Publicado en formato digital: Dra. Lic. Liliana Ramírez y Prof. Romina Claret. LA SALUD AMBIENTAL MEDIDA A PARTIR DE DATOS CENSALES. UNA MIRADA SOBRE EL AREA METROPOLITANA DEL GRAN RESISTENCIA Y PRESIDENCIA ROQUE SAENZ PEÑA. Revista Geográfica Digital. IGUNNE. Facultad de Humanidades. UNNE. Año 11. № 21. Enero - Junio 2014. ISSN 1668-5180 Resistencia, Chaco. En: http://hum.unne.edu.ar/revistas/geoweb/default.htm 